2017 - Volume: 18 Number: 5

Page: 1098 - 1106

DOI : $10.18038 /$ aubtda. 310676

Received: 05 May 2017 Revised: 20 August 2017 Accepted: 26 october 2017

\title{
KINETICS OF ESTERIFICATION OF ACETIC ACID WITH 2-ETHYLHEXANOL IN THE PRESENCE OF AMBERLYST 36
}

\author{
Sema AKYALÇIN* \\ Department of Chemical Engineering, Faculty of Engineering, Anadolu University, Eskisehir, Turkey
}

\begin{abstract}
The kinetics of esterification of acetic acid with 2-ethylhexanol catalyzed by Amberlyst 36 was studied in a stirred batch reactor. The equilibrium constant, $K_{c}$, was found to be 81 and it is independent of temperature within the range of 333 to $363 \mathrm{~K}$. The uncatalyzed reaction was proved to follow a second-order reversible reaction model. In the presence of Amberlyst 36, experimental data well fitted with a pseudo-homogeneous model.
\end{abstract}

Keywords: Esterification, Reaction kinetics, 2-ethylhexyl acetate, Amberlyst 36

\section{INTRODUCTION}

Organic esters are used in different industries such as flavoring, perfumery, pharmaceuticals, plastics, solvents, and intermediates [1]. 2-Ethylhexyl acetate has a high boiling point and it is a suitable solvent for cellulose nitrate and many natural and synthetic resins. It is used in the coatings and petroleum industries [2].

Esters are mostly produced by the reaction of a carboxylic acid with an alcohol in the presence of an acid catalyst. This reaction proceeds very slowly without strong acid [3]. Therefore, homogeneous or heterogeneous catalysts can be used in order to increase the reaction rate. Heterogeneous catalysts offer inherent advantages over homogenous catalysts such as elimination of corrosive environment, easy regeneration, and easy catalyst separation from the reaction mixture. Furthermore, heterogeneous catalysis improved selectivity of the product [4]. Therefore, the replacement of homogeneous catalyst with the heterogeneous catalysts is useful in the production of organic esters.

A variety of solid acid catalysts, e.g., ion exchange resins [5-12], zeolites [13, 14] and acidic clay catalysts $[15,16]$ were used in the different esterification reactions. Although there are many solid catalysts, acidic resins are the most commonly used in liquid phase esterification reactions since they are proven effective catalysts for these reactions $[17,18]$.

There have been great number of studies in the literature about the esterification of acetic acid with different alcohol in the presence of Amberlyst type catalyst [5-7, 9-12]. Schmid et al. studied the kinetics of esterification of ethylene glycol with acetic acid over Amberlyst 36. They report that a pseudo homogeneous model well describe the experimental results of the heterogeneous catalyzed esterification reaction and of the hydrolysis reaction [10]. Akbay and Altiokka investigated the kinetics of esterification of acetic acid with amyl alcohol using Amberlyst-36 as a heterogeneous catalyst. They stated that the second-order reversible kinetic model describes the experimental data very well [11]. Akyalcin and Altiokka studied the production of 1-octyl acetate and they used the Eley-Rideal model to describe the kinetics of esterification of acetic acid with 1-octanol over Amberlyst-36 [12].

There have been a limited number of studies related with the production of 2-ethylhexyl acetate in the literature. Ragaini et al. studied the kinetic of esterification of diluted acetic acid with 2-ethyl-1-hexanol using Amberlyst 15 as solid catalyst. They proposed the mathematical model by considering all the 
diffusional and reactive steps between the aqueous and organic phases [19]. Rajkumar and Ranga Rao prepared and characterized the catalyst, which was 12-tungstophosphoric acid supported on hydrous zirconia, for liquid-phase esterification of 2-ethyl-1-hexanol with acetic acid. They report that the conversion of 2-ethyl-1-hexanol reached to $90 \%$ over $0.1 \mathrm{~g}$ of catalyst, which was 35 wt $\% 12$ tungstophosphoric acid loading on hydrous zirconia, using alcohol/acid mol ratio $1 / 2$ at $100{ }^{\circ} \mathrm{C}$ in $5 \mathrm{~h}$ reaction time and selectivity of ester is $100 \%$ [20]. Gyani and Mahani have also studied the same reaction over Amberlyst 15 in a batch reactor. They performed the kinetic modeling by using modified activity based on Langmuir-Hinshelwood-Hougen-Watson model [21]. Patidar and Mahajani investigated the esterification of 2-ethylhexanol with acetic acid catalyzed by Amberlyst 15 to produce 2-ethylhexyl acetate in a reactive distillation column using toluene. They also studied the same reaction catalyzed by homogeneous p-toluenesulfonic acid and they compare the results of two processes [22].

In the present work, the kinetic model was established to represent the esterification of acetic acid with 2-ethylhexanol in the presence of Amberlyst 36, which has high thermal stability (working temperature up to $150^{\circ} \mathrm{C}$ ), high density of acidic sites, and less corrosivity.

\section{MATERIALS AND METHODS}

\subsection{Materials}

Acetic acid ( $\geq 99.8 \%)$, 2-Ethylhexanol ( $\geq 99 \%)$ and toluene ( $\geq 99.7 \%)$ were purchased from Sigma Aldrich. Amberlyst 36, a macroreticular sulfonic acid resin catalyst in bead form and was developed particularly for heterogeneous catalysis, was used as a catalyst in all experiments. The properties of Amberlyst 36 reported by manufacturer are summarized in Table 1 . The catalyst was dried at $343 \mathrm{~K}$ under vacuum before use.

Table 1. Properties of Heterogeneous Catalyst

\begin{tabular}{ll}
\hline & Amberlsyt 36 \\
\hline Concentration of acid sites $(\mathrm{eq} / \mathrm{kg})$ & $\geq 5.40$ \\
Water content $(\%)$ & 55 \\
Particle size $(\mathrm{mm})$ & $0.425-0.800$ \\
Surface area $\left(\mathrm{m}^{2} / \mathrm{g}\right)$ & 33 \\
Max. operating temperature $\left({ }^{\circ} \mathrm{C}\right)$ & 150 \\
\hline
\end{tabular}

\subsection{Apparatus}

The experiments were performed in a three-necked cylindrical Pyrex flask of $300 \mathrm{ml}$ capacity fitted with a sample device, a spiral coil condenser, and a thermometer. The temperature control (with precision of $\pm 0.1 \mathrm{~K}$ ) of reaction system was provided by circulating water from a thermostat into the reactor jacket. A magnetic stirrer performed mixing of the reaction fluid.

\subsection{Procedure}

At the beginning, toluene as the solvent, 2-Ethylhexanol $(2 \mathrm{EOH})$ and a known amount of the catalyst were placed in the reactor and the stirring started. The temperature of the reaction mixture was increased up to the desired value and kept constant during the reaction. As soon as the temperature of the reaction mixture reaches its steady state value, acetic acid (A) was added into the reaction mixture and the first sample was withdrawn from the reactor to determine the initial composition of the reaction mixture. After that, $1 \mathrm{~mL}$ sample was periodically taken from the reactor for the analysis and it is immediately cool down in order to stop further progression of the reaction after sampling. 


\subsection{Analysis}

The concentration of acetic acid in all samples was analyzed by standardized $0.05 \mathrm{~N} \mathrm{NaOH}$. The water content measured by Karl Fischer titration (Metrohm KF-784) confirmed that the amount of water calculated from stoichiometric mass balance, which indicates that there is no by-products formation. Thereafter, the concentrations of alcohol and ester were determined from mass balance calculations based on the stoichiometric equations.

\section{RESULTS AND DISCUSSION}

The experiments were performed in a stirred batch reactor to investigate the effects of temperature, catalyst loading and mole ratios of reactants on the esterification reaction rate. In each experiment, a single parameter under investigation was varied while keeping all other parameters fixed.

It is important to study the influence of external and internal mass transfer resistances before the kinetic study. The effect of the external mass transfer resistance on the reaction rate is directly related to the stirring speed [23]. Gyani and Mahajani investigated the reaction rate of esterification of acetic acid with 2-ethylhexanol in a wide range of stirring speed (600-1100 rpm). They state that a stirrer speed of 1000 $1100 \mathrm{rpm}$ had no effect on the conversion [21]. Therefore; all experiments were carried out at a constant stirring speed of $1100 \mathrm{rpm}$ to eliminate the influence of external mass transfer resistance.

Additionally, the temperature criteria was applied to investigate the effect of internal diffusion since internal diffusion step is less temperature dependency than reaction step [24, 25].

\subsection{Effect of Temperature and Determination of Equilibrium Constant}

The esterification reactions were performed at $333,343,353$, and $363 \mathrm{~K}\left(M=\frac{C_{2 E O H_{0}}}{C_{A_{0}}} ; M=1\right.$ with $C_{A_{0}}=1.00 \mathrm{~mol} / \mathrm{L}$ in toluene) with $5 \mathrm{wt} \%$ catalyst loading defined as weight percent of catalyst based on the total reaction mixture. The effects of temperature on the conversion of acetic acid $(A)$ are given in Figure 1.

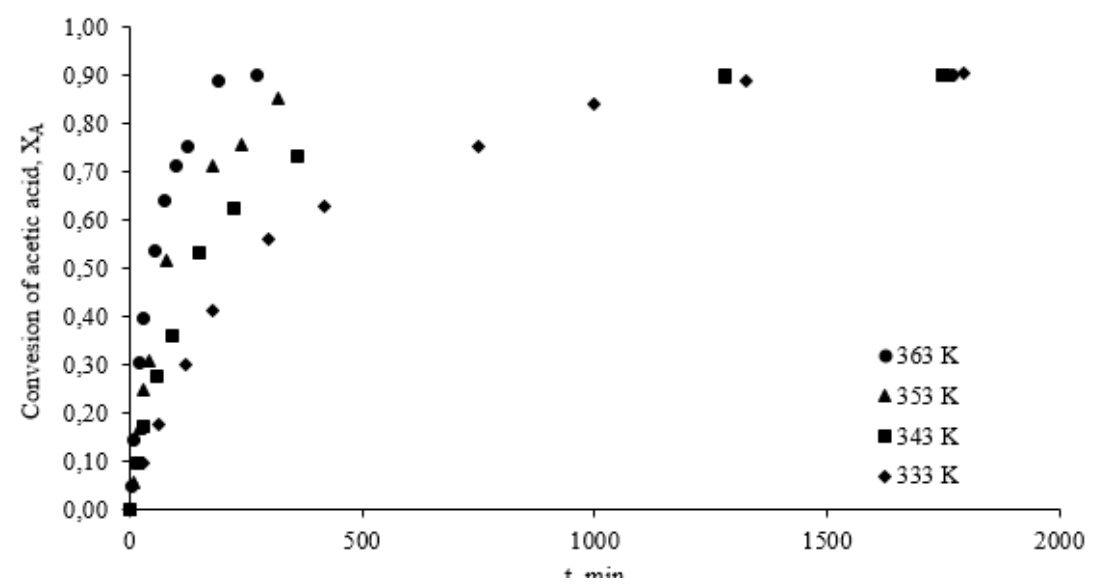

Figure 1. Effect of temperature on the conversion of acetic acid, $M=1$ with $C_{A_{0}}=1.00 \mathrm{~mol} / \mathrm{L}$ in toluene, catalyst loading of $5 \mathrm{wt} \%$.

Figure 1 shows that the reaction rate is highly depend on temperature. Thus, it is reasonable to neglect the effect of external diffusion and internal pore diffusion. These results confirm the literature findings claiming that the influence of external and internal diffusion can be neglected for the esterification of acetic acid with different alcohols catalyzed by Amberlyst 36 [6, 10-12]. 
The equilibrium constant, $K_{c}$, was calculated, from the equilibrium concentration, to be 81 , which is independent of temperature within the range stated above. $K_{c}$ was determined by Eq. 1.

$$
K_{c}=\frac{C_{E_{e q}} C_{W_{e q}}}{C_{2 E O H} C_{e q} C_{e q}}=\frac{x_{A_{e q}}^{2}}{\left(1-x_{A_{e q}}\right)\left(M-x_{A_{e q}}\right)}
$$

where $x_{A_{e q}}$ is the equilibrium conversion of acetic acid. The standard reaction enthalpy, $\Delta \mathrm{h}_{\mathrm{r}}^{\circ}$, calculated from the standard formation enthalpies of the reaction components given in Table 2, was found to be $0.61 \mathrm{~kJ} / \mathrm{mol}$ verifying the conclusion that $K_{c}$ is independent of temperature since it is relatively close to zero. The standard formation enthalpies of the reaction components were given in Table 2.

Table 2. Standard formation enthalpies of the reaction components

\begin{tabular}{lll}
\hline Component & $\left.\Delta \mathbf{h}_{\mathrm{f}}^{\circ} \mathbf{( k j} / \mathbf{m o l}\right)$ & Ref. \\
\hline Water & -285.83 & {$[12]$} \\
2-Ethylhexyl acetate & -631.2 & {$[2]$} \\
2-Ethylhexanol & -433.14 & {$[26]$} \\
Acetic acid & -484.5 & {$[12]$} \\
\hline
\end{tabular}

The theoretical equilibrium constant, $K_{a}$, was also calculated to be 82.2 at $333 \mathrm{~K}$ to 83.7 at $363 \mathrm{~K}$ by using the thermodynamic data. For this purpose, the standard Gibbs energy of reaction, $\Delta \mathrm{G}_{\mathrm{r}}{ }^{\circ}$ was also determined from the standard Gibbs energies of the reaction components. The standard Gibbs energies of 2-ethylhexyl acetate and 2-ethylhexanol were calculated by the Joback Group Contribution Method and that of the others were already tabulated in the literature [27]. In this calculation, the activity of the component $i$ at equilibrium can be defined as $a_{i}=\gamma_{i} \frac{C_{i}}{C_{t}}$ and $K_{a}$ is equal to $K_{c} K_{\gamma}$.

\subsection{Effect of Catalyst Loading}

To determine the effect of catalyst loading on the esterification reaction rate, the experiments were carried out by varying the catalyst loadings of $0,0.92,5$, and $7.5 \mathrm{wt} \%$ with $M=1.0, C_{A_{0}}=1.00 \mathrm{~mol} / \mathrm{L}$ and $\mathrm{T}=363 \mathrm{~K}$. The initial reaction rate shown in Figure 2 was calculated from Eq. 2 using a conversion lower than $10 \%$, since the esterification reaction rate can be considered to be linear up to $10 \%$ conversion.

$$
-r_{A, 0}=C_{A_{0}} \frac{X_{A}}{t}
$$

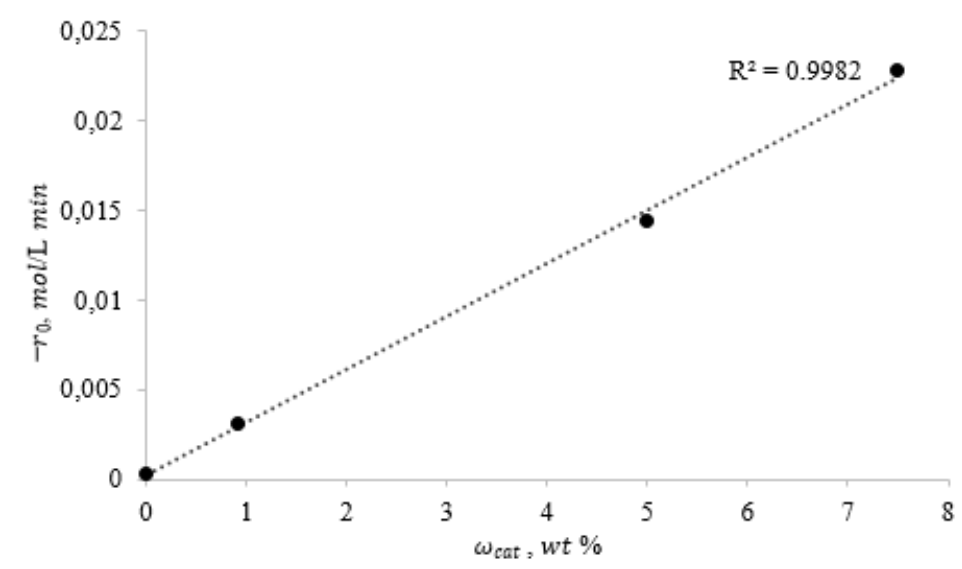

Figure 2. Effect of catalyst loading on the initial reaction rate at $363 \mathrm{~K}, M=1.0$ with $C_{A_{0}}=1.00 \mathrm{~mol} / \mathrm{L}$ 
Figure 2 shows that the esterification reaction rate increases linearly with increasing catalyst loading, since the active surface area is proportional to the amount of catalyst. The mathematical expression for the initial reaction rate, $-r_{0}$ as a function of the catalyst loading was obtained from Figure 2:

$$
-r_{0}\left(\frac{m o l}{L \cdot \min }\right)=0.00296 \omega_{c a t}(w t \%)+0.00023
$$

where $0.00023 \mathrm{~mol} /(\mathrm{L} \cdot \mathrm{min})$ corresponds to the initial reaction rate of the uncatalyzed reaction under the expressed conditions. This result is compatible with the uncatalyzed reaction rate obtained experimentally as $0.00026 \mathrm{~mol} /(\mathrm{L} \cdot \mathrm{min})$.

\subsection{Effect of Reactants Mole Ratio}

To investigate the effect of reactants mole ratio, esterification reactions were performed with $5 \mathrm{wt} \%$ catalyst loading at $363 \mathrm{~K}$ while the molar ratio of alcohol/acid was varied as $1 / 1,2 / 1$, and 3/1 with $C_{A_{0}}=1.00 \mathrm{~mol} / \mathrm{L}$, and the molar ratio of acid/alcohol was varied as $1 / 1$ and $3 / 1$ with $C_{2 E O H_{0}}=1.00 \mathrm{~mol} / \mathrm{L}$.

The initial reaction rate based on limiting reactant given in Figure 3 was calculated from Eq. 2 using a conversion lower than $10 \%$, since the esterification reaction rate can be considered to be linear up to 10 $\%$ conversion.

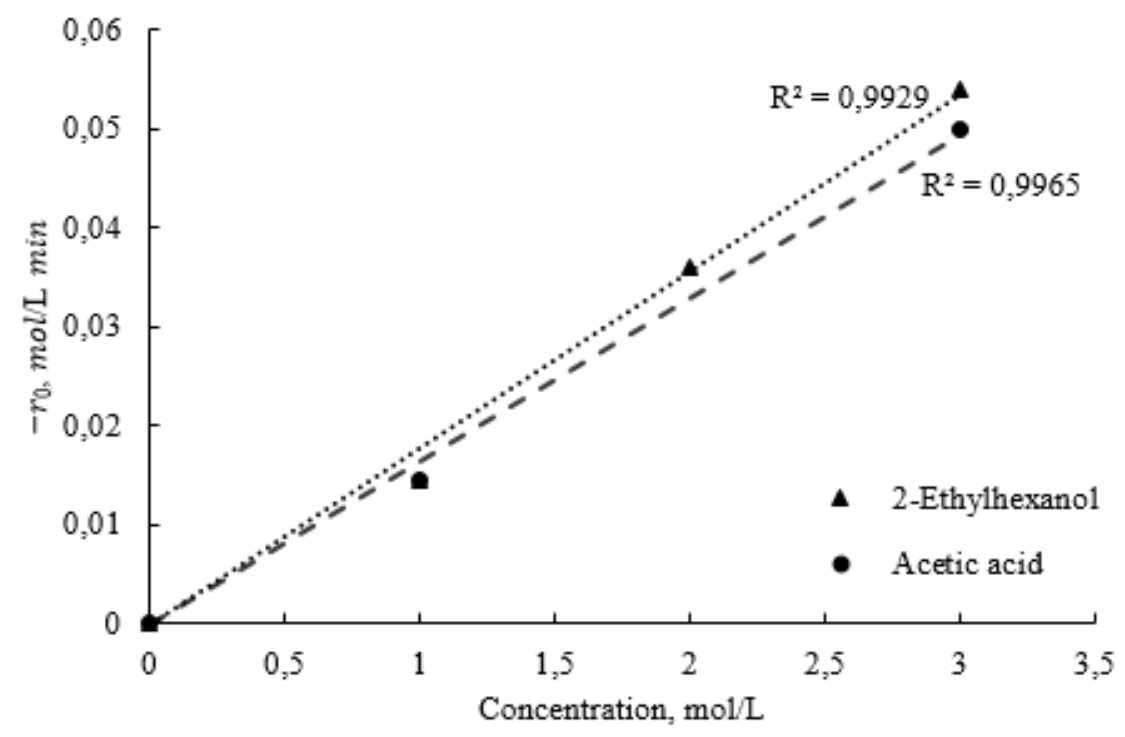

Figure 3. Effect of reactant concentration on the initial reaction rate at $363 \mathrm{~K}$ and a catalyst loading of $5 \mathrm{wt} \%$.

Figure 3 shows that the initial reaction rate increases linearly by increasing alcohol and acid concentrations, which indicate that 2-ethylhexanol and acetic acid were not adsorbed on the surface of the catalyst.

Additionally, the esterification of acetic acid with 2-ethylhexanol is a reversible reaction, and the amount of ester formed was controlled by the position of equilibrium [28]. Consequently, the excess usage of 2ethylhexanol increased the conversion of acetic acid up to $97 \%$.

\subsubsection{Reaction Mechanism and Kinetics}

The esterification of acetic acid with 2-ethylhexanol can be given as follows: 


$$
\mathrm{CH}_{3} \mathrm{COOH}+\mathrm{CH}_{3}\left(\mathrm{CH}_{2}\right)_{3} \mathrm{CH}\left(\mathrm{CH}_{2} \mathrm{CH}_{3}\right) \mathrm{CH}_{2} \mathrm{OH} \leftrightarrow \mathrm{H}_{3} \mathrm{CCO}_{2} \mathrm{CH}_{2} \mathrm{CH}\left(\mathrm{C}_{2} \mathrm{H}_{5}\right)\left(\mathrm{CH}_{2}\right)_{3} \mathrm{CH}_{3}+\mathrm{H}_{2} \mathrm{O}
$$
Acetic acid $(A)$
2-Ethylhexanol (2EOH)
2-Ethylhexyl acetate $(E)$
Water $(W)$

The kinetics of an esterification reaction can be represented using a pseudo-homogeneous or EleyRideal or the Langmuir- Hinshelwood- Hougen-Watson mechanisms. The conclusion obtained from Figure 3 implies that the pseudo-homogeneous model can be used to represent the reaction mechanism. In the literature, a pseudo-homogeneous model is employed to express the esterification reactions with acidic resins as catalyst $[10,11,29]$. Then, the reaction rate expression is given as:

$$
-r_{A}=k_{1}\left(C_{A} C_{2 E O H}-\frac{C_{E} C_{W}}{K_{C}}\right)
$$

When the reaction rate expression is rearranged in terms of acetic acid conversion, the following equation is obtained:

$$
-r_{A}=C_{A_{0}} \frac{d X_{A}}{d t}=k_{1} C_{A_{0}}^{2}\left[\left(1-X_{A}\right)\left(M-X_{A}\right)-\left(\frac{X_{A}^{2}}{K_{c}}\right)\right]
$$

since there is no product initially. The integrated form of Eq. 6 in its linear form can be given as:

$$
\ln \left[\left(\frac{c_{3}+c_{2}-2 c_{1} X}{c_{2}-c_{3}-2 c_{1} X}\right)\left(\frac{c_{2}-c_{3}}{c_{2}+c_{3}}\right)\right]=c_{3} k_{1} C_{A_{0}} t
$$

where $c_{1}=\left(1-\frac{1}{K_{e}}\right), c_{2}=M+1$ and $c_{3}=\left[c_{2}^{2}-4 c_{1} M\right]^{1 / 2}$.

Applying Eq. 7 to the experimental data, Figure 4 was obtained.

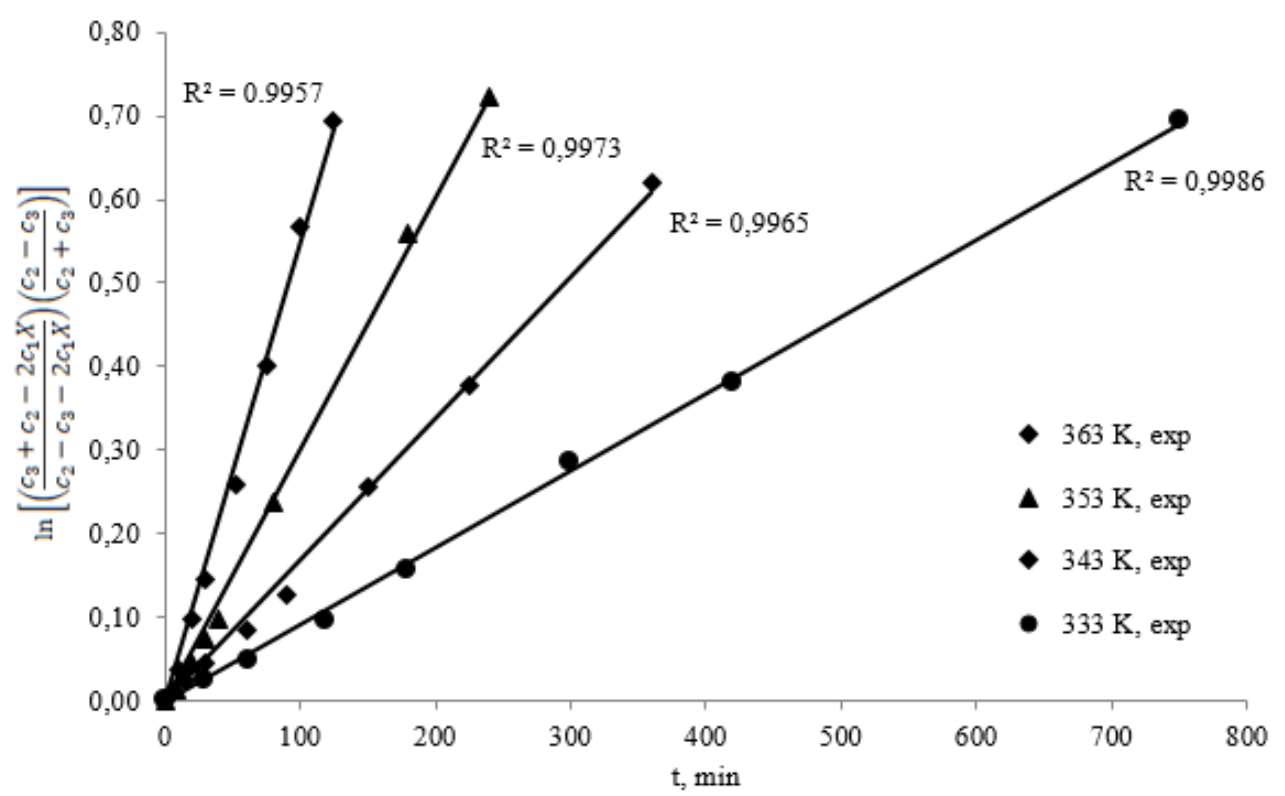

Figure 4. Adopted Eq. 7 to the experimental data at different temperatures with $5 \mathrm{wt} \%$ catalyst loading

The forward reaction rate constant, $k_{1}$, was found from the slopes of lines in Figure 4 at different temperatures with 5 wt \% catalyst loading. The results are given in Table 3 . 
Akyalçın / Anadolu Univ. J. of Sci. and Technology - A - Appl. Sci. and Eng. 18 (5) - 2017

Table 3. Calculated values of the forward reaction rate constant, $k_{1}$, at different temperatures with $5 \mathrm{wt} \%$ catalyst loading.

\begin{tabular}{lllll}
\hline $\mathrm{T}(\mathrm{K})$ & 333 & 343 & 353 & 363 \\
\hline$k_{1}(\mathrm{~L} /(\mathrm{mol} \cdot \mathrm{min}))$ & 0.00413 & 0.00761 & 0.0136 & 0.0233 \\
\hline
\end{tabular}

Applying the Arrhenius equation using the values given in Table 3, the temperature dependency of the forward reaction rate constant and the activation energy were found to be:

$$
k_{1}\left(\frac{L}{\text { mol.min }}\right)=\exp \left(15.46-\frac{6976}{T}\right) ; \quad \mathrm{E}_{\mathrm{a}}=58.0 \mathrm{~kJ} / \mathrm{mol}
$$

To determine the uncatalyzed reaction rate constant, the experiments were also performed at 353 and $363 \mathrm{~K}, M=1.0$ with $C_{A_{0}}=1.00 \mathrm{~mol} / \mathrm{L}$ in toluene.

Applying Eq. 7 to the uncatalyzed experimental data, Figure 5 was obtained and the forward reaction rate constant for uncatalyzed reactions, $k_{1}^{\prime}$, was found to be $9.108^{*} 10^{-3}$ and $1.719^{*} 10^{-2} \mathrm{~L} /(\mathrm{mol} \cdot \mathrm{h})$ at 353 and $363 \mathrm{~K}$, respectively. Using these values in Arrhenius equation, the reaction rate constant as a function of temperature were determined to be:

$k_{1}^{\prime}\left(\frac{L}{m o l \cdot h}\right)=\exp \left(18.36-\frac{8139}{T}\right) ;$

where $\mathrm{T}$ is the absolute temperature in Kelvin. The reverse reaction rate constant, $k_{2}$, can also be calculated by using the equilibrium constant, $\mathrm{K}_{\mathrm{c}}$ is known to be 81 .

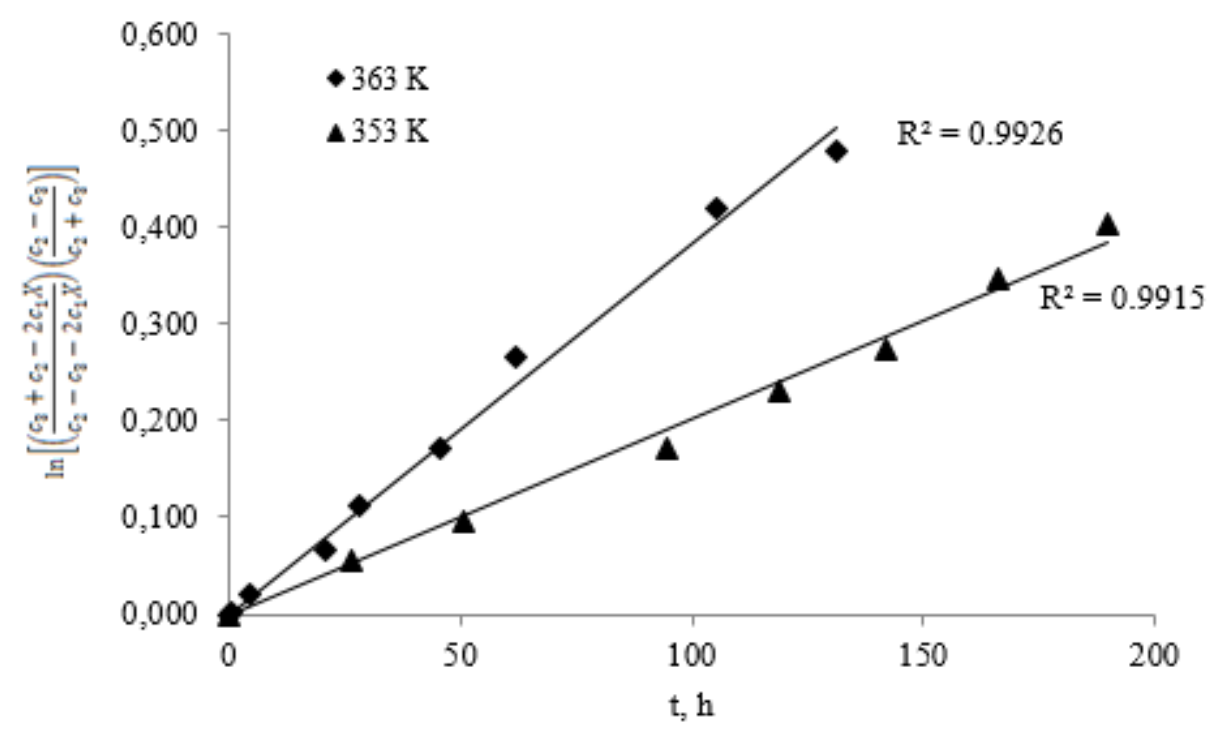

Figure 5. Adopted Eq. 7 to the uncatalyzed experimental data at $353 \mathrm{~K}$ and $363 \mathrm{~K}$

\section{CONCLUSION}

The kinetics of esterification of acetic acid with 2-ethylhexanol has been studied with Amberlyst 36 in a batch reactor. It was found that the reaction follows the second order reversible reaction mechanism in which the reaction rate expression, based on the consumption of acetic acid, can be given by Eq. 6. It is also observed that the reaction rate increases linearly with increasing catalyst loading and the mathematical expression is given with Eq. 3. The formation of 2-ethylhexyl acetate from acetic acid and 2-ethylhexanol was also studied in the literature using Amberlyst 15 as catalyst. It was reported that 
Akyalçın / Anadolu Univ. J. of Sci. and Technology - A - Appl. Sci. and Eng. 18 (5) - 2017

activation energy of the reaction is $72.2 \mathrm{~kJ} / \mathrm{mol}$ [21]. In the present study, this was found as $58.0 \mathrm{~kJ} / \mathrm{mol}$. This result indicates that Amberlyst 36 is more effective than Amberlyst 15. Therefore, Amberlyst 36, as a strongly acidic cation exchange resin, is recommended for the esterification of acetic acid with 2ethylhexanol.

\section{REFERENCES}

[1] Kirk R. E. Othmer D. F. In Encyclopedia of Chemical Technology, CD-ROM, $4^{\text {th }}$ Ed. New York: John Wiley and Sons, 2001.

[2] BASF, Technical Information, Petrochemicals: 2-Ethylhexyl Acetate, 2016. http://www.solvents.basf.com/portal/streamer?fid $=278918$

[3] Solomons, T. W. G. Fundamentals of Organic Chemistry. Canada: John Wiley and Sons, 1982.

[4] Altiokka, M. R., Citak, A. Kinetics study of esterification of acetic acid with isobutanol in the presence of amberlite catalyst. Appl. Catal. A: Gen. 2003; 239: 141-148.

[5] Blagov, S., Parada, S., Bailer, O., Moritz, P., Lam, D., Weinand, R., Hasse, H. Influence of ionexchange resin catalysts on side reactions of the esterification of n-butanol with acetic acid. Chem. Eng. Sci. 2006; 61: 753-765.

[6] Tsai, Y.-T., Lin, H.-M., Lee, M.-J. Kinetics behavior of esterification of acetic acid with methanol over Amberlyst 36. Chem. Eng. J. 2011; 171: 1367-1372.

[7] Richard, R., Guillaume, D., Jacquin, M. Kinetics modeling of the heterogeneously catalyzed esterification of 2,3-Butanediol with acetic acid. Ind. Eng. Chem. Res. 2016; 55: 5247-5256.

[8] Leyva, F., Orjuela, A., Miller, D. J., Gil, I., Vargas, J., Rodríguez, G. Kinetics of propionic acid and isoamyl alcohol liquid esterification with Amberlyst 70 as catalyst. Ind. Eng. Chem. Res. 2013; 52: 18153-18161.

[9] Ali, S. H., Merchant, S. Q. Kinetics of the esterification of acetic acid with 2-propanol: Impact of different acidic cation exchange resins on reaction mechanism. Int J Chem Kinet 2006; 38: 593-612.

[10] Schmid, B., Dölker, M., Gmehling, J. Esterification of Ethylene Glycol with Acetic Acid Catalyzed by Amberlyst 36. Ind. Eng. Chem. Res. 2008; 47: 698-703.

[11] Akbay, E. Ö., Altiokka, M. R. Kinetics of esterification of acetic acid with n-amyl alcohol in the presence of Amberlyst-36. Appl. Catal. A: Gen. 2011; 396: 14-19.

[12] Akyalçın, S. Altıokka, M. R. Kinetics of esterification of acetic acid with 1-octanol in the presence of Amberlyst 36. Appl. Catal. A: Gen. 2012; 429-430: 79-84.

[13] Schildhauer, T. J., Hoek, I., Kapteijn, F., Moulijn, J. A. Zeolite BEA catalysed esterification of hexanoic acid wih 1-octanol: Kinetics, side reactions and the role of water. Appl. Catal. A: Gen. 2009; 358: 141-145.

[14] Kirumakki, S. R., Nagaraju, N., Chary, K. V. R. Esterification of alcohols with acetic acid over zeolites H $\beta$, HY and HZSM5. Appl. Catal. A: Gen. 2006; 299: 185-192. 
Akyalçın / Anadolu Univ. J. of Sci. and Technology - A - Appl. Sci. and Eng. 18 (5) - 2017

[15] Do Nascimento, L. A. S., Angélica, R. S., Da Costa, C. E. F., Zamian, J. R., Da Rocha Filho, G. N. Comparative study between catalysts for esterification prepared from kaolins. Appl. Clay Sci. 2011; 51: 267-273.

[16] Zatta, L., Gardolinski, J. E. F. da C., Wypych, F. Raw halloysite as reusable heterogeneous catalyst for esterification of lauric acid. Appl. Clay Sci. 2011; 51: 165-169.

[17] Peters, T. A., Benes, N. E., Holmen, A., Keurentjes, J.T.F. Comparison of commercial solid acid catalysts for the esterification of acetic acid with butanol. Appl. Catal. A: Gen. 2006; 297: 182-188.

[18] Liu, W. T., Tan, C. S. Liquid-phase esterification of propionic acid with n-butanol. Ind. Eng. Chem. Res. 2001; 40: $3281-3286$.

[19] Ragaini, V., Bianchi, C.L., Pirola, C. Kinetics of esterification of diluted acetic acid with pure 2ethyl-1-hexanol. Chemical Eng. J. 2007; 131: 257-262.

[20] Rajkumar, T., Ranga Rao, G. Porous hydrous zirconia supported 12-tungstophosphoric acid catalysts for liquid-phase esterification of 2-ethyl-1-hexanol. J. Mol. Catal A: Chem. 2008; 295:1-9.

[21] Gyani, V. C., Mahajani, S. Reactive chromatography for the synthesis of 2- Ethylhexyl acetate. Sep. Sci. Technol. 2008; 43: 2245-2268.

[22] Patidar, P., Mahajani, S. Entrainer-Based Reactive Distillation for the Synthesis of 2-Ethylhexyl Acetate. Ind. Eng. Chem. Res. 2012; 51: 8748-8759.

[23] Ali, S. H., Tarakmah, A., Merchant, S. Q., Al-Sahhaf, T. Synthesis of esters: Development of the rate expression for the Dowex $50 \mathrm{Wx} 8-400$ catalyzed esterification of propionic acid with 1-propanol Chem. Eng. Sci. 2007; 62: 3197-3217.

[24] Foggler, H. S. Elements of Chemical Reaction Engineering. 3rd ed. New Jersey, USA: Prentice Hall, 1999.

[25] Bartholomew, C. H., Farrauto, R. J. Fundamentals of Industrial Catalytic Processes. 2nd ed. USA: John Wiley \&Sons, 2006.

[26] BASF, Technical leaflet, Petrochemicals: 1999. http://www.solvents.basf.com/portal/load/fid245412/Technical\%20Spec\%20$\% 202 \% 20$ Ethylhexanol_BPC.pdf

[27] Poling, B.E., Prausnitz, J. M., O'Connell, J.P. The Properties of Gases and Liquids. 5th ed. USA: McGraw-Hill, 2001.

[28] Teo, H. T. R., Saha, B. Heterogeneous Catalyzed Esterification of Acetic Acid with Isoamyl Alcohol: Kinetic Studies. J. Catal. 2004; 228: 174-182.

[29] İzci, A., Bodur, F. Liquid-phase esterification of acetic acid with isobutanol catalyzed by ionexchange resins. React. Funct. Polym. 2007; 67: 1458-1464. 